\title{
基于病例-对照设计的中国马流感发生的集聚度 探测研究
}

\author{
张志诚 ${ }^{(1)}$, 王志亮 ${ }^{(1 *}$, 侯哲生 ${ }^{(2)}$, 相文华 ${ }^{(3)}$, 王力俭 ${ }^{(4 *}$ \\ (1) 中国动物卫生与流行病学中心国家外来病研究中心, 青岛 266032; \\ (2) 烟台大学土木工程学院, 烟台 264005; \\ (3) 中国农业科学院哈尔滨兽医研究所, 哈尔滨 150001; \\ (4) 新疆畜牧科学院, 乌鲁木齐 830000 \\ * 联系人, E-mail: Zhiliangwang111@yahoo.com; xjxkywlj@126.com \\ 2011-11-07 收稿, 2012-03-18 接受 \\ 国家农业公益性行业科研专项(201103008 和 200903037)资助
}

\begin{abstract}
摘要 基于病例-对照设计、地理风险格局和集聚度探测等方法, 开展我国马流行性感冒病例 分布特点研究. 研究显示, 我国是马属动物的养殖大国, 马流行性感冒在我国局部地区的马属 动物群体中曾在较大范围发生. 回顾性分析表明, 我国马流感病例主要分布在西北和东北局 部地区, 2000 2007 年病例集聚度探测表明, 新疆伊犁州和巴音郭楞蒙古自治州交界地区坐标 为(6460039.00, 4277548.50) $(P<0.001, R=7487976.06 \mathrm{M}, R R=273.94)$ 病例区集聚度为最高, $R R$ 值达到 273.94, 显示该病例区及附近区域很有可能存在马流感疫情发生所需要的必要风险因 素, 提示应该加强对该区域马属动物的风险监管和主动监测. 此外, 在青海和甘肃等省、市和 自治区的病例报道预示有沿新-青-甘-蒙一线传播态势。基于病例-对照设计和集聚度探测，初 步明确了现阶段我国马流感发生风险主要集中在西北局部地区，应适时加强对我国新、甘、蒙 等西北地区马流感的主动监测和马属动物的移动监管.
\end{abstract}

\section{关键词}

病例-对照

集聚度

马流行性感冒 地理风险格局 主动监测
马流行性感冒 (equine influenza, EI)是由马流感 病毒引起的一种最为常见的马属动物呼吸道传染病, 其症状包括发热、结膜潮红、咳嗽、流浆液性或脓性 鼻液等, 怀孕母马可发生流产, 病理表现包括急性支 气管炎、细支气管炎、间质性肺炎，也可发生继发性 支气管肺炎 ${ }^{[1 \sim 4]}$. 由于该病发病急、传播速度快, 世界 动物卫生组织(Office International Des Épizooties, OIE) 规定为法定报告动物疫病, 我国目前只列为三类动 物疫病. 马流感易感动物多, 马、驴、骡等马属动物 是马流感病毒最为常见的易感动物, 犬只等其他动 物感染马流感病毒并扩散也引起了广泛的关注 ${ }^{[4 \sim 6]}$. 马流感在全球各地发生较为普遍 ${ }^{[7]}$, 其最为显著的流 行病学特征是传播速度快、潜伏期短、多呈暴发性流
行, 1 周左右同群绝大多数易感马感染发病 ${ }^{[1 \sim 3]}$. 病马 咳嗽喷出含有病毒的飞沫, 被其他马吸人是马流感 的主要感染方式. 此外马流感病毒还可随风传播, 最 远的报道距离达 $8 \mathrm{~km}^{[7]}$. 人的衣服、车辆、马厩、尿 液或饲料污染了马流感病毒, 也会引起马流感的传 播. 混群和马属动物远距离移动是马流感迅速发生 和大范围扩散的重要风险因素 ${ }^{[8]}$. 目前我国对马流感 的研究主要集中在分子流行病学, 血凝抑制实验、

ELISA, RT-PCR 等标准检测方法以及疫苗研制等方 面 ${ }^{[2,9]}$, 而从疫病流行病学和风险管理角度对病例分

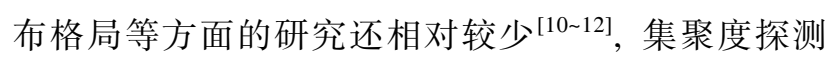
的方法在兽医流行病学领域更是鲜有人涉及. 本文 的研究是 2008 年向北京奥组委和国际奥委会提供的

英文引用格式: Zhang Z C, Wang Z L, Hou Z S, et al. Case-control study on cluster detection of equine influenza in China (in Chinese). Chin Sci Bull (Chin Ver), 2012, 57: 2192-2199, doi: 10.1360/972011-384 
“中国马流感发生的风险评估报告”的一部分，其主 要方法是基于对马流感发生病例的病例-对照(casecontrol)设计, 开展回顾性调查和流行病学数据挖掘, 同时结合地理风险格局分析 ${ }^{[13 \sim 18]}$ 和集聚度探测的方

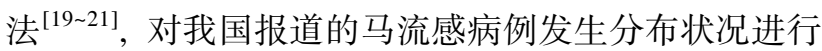
分析, 为我国马流感防控和马属动物的风险管理提 供技术支持和参考。

\section{1 数据来源及方法}

\section{1 数据来源}

马流感病例数据主要来源于中国动物疫病志和 有关省、市和自治区的动物疫病志 ${ }^{[22 ~ 24]}$, 科技文献挖 掘和国家马病中心提供了部分马流感流行病学调查 资料和信息, 相关养殖背景数据来自 2000 2007 年中 国畜牧业年鉴. 文中所用的地理信息数据来自国家 测绘局基础地理信息中心 1:400 万电子地图.

\section{2 空间定位和表达}

我国历年发生的马流感在全国各地报道发生的 空间分异状况通过 ESRI 公司的 ArcInfo9.0 来进行空 间表达和描述.

\section{3 实验设计}

马流感是我国三类动物疫病, 长期以来马流感 一直不是我国动物疫病防控的重点. 文中所收集和 整理挖掘的马流感历史病例数据大都是间接来自科 技文献以及档案、收集整理的信息. 鉴于马流感发生 的病程急、发病和扩散快、传播迅速的特点, 一起报 道的病例数据在实际场景中大都是在报道区域内或 特定县区一簇或几簇马属动物群体的发病. 基于这 种状况的认识和考虑, 在数据处理时, 利用回顾性分 析的思路去开展簇病例流行病学数据挖掘和整理, 收集每一起“病例”发生的时间特征、发生位置的特 征、发病宿主特征以及发生的背景特征等信息. 设定 两类样本, 第一类样本是报道马流感病例的病例区, 第二类样本是指未报道发生病例的对照区, 病例区 和对照区构成整个实验样本框中的两类样本, 共计 2357 个样本区，样本框涵盖全国所有区域.

\section{4 模型和方法应用}

（i ）病例-对照方法. 病例-对照方法是现代流
行病学最为经典的研究方法之一, 在流行病学调查 的回顾性分析、横断面研究、病因探索、模型假设和 验证等多个方面都有广泛的应用. 在医学地理上，应 用病例-对照的设计和研究方法对传染性事件发生的 风险控制和疫病预防有着久远的历史. 早在 1854 年, John Snow 博士就利用病例-对照设计的方法对英国 伦敦发生的霍乱大流行进行了开创性的研究, 为传 统的传染性流行病的流行和扩散研究提供了新的思 路和方法, 为伦敦的霍乱大流行的有效控制起到了 关键性的作用 ${ }^{[25,26]}$, 同时为现代公共卫生和流行病 学空间分析的研究方法开拓了新的领域. 目前病例对照设计及其研究方法在我国兽医流行病学领域还 鲜有人涉及.

（ii）地理风险格局分析．地理风险格局分析主 要依托对地理事件的分布模式来开展研究. 格局分 析是生态学的传统方法, 最早源于种群生态学、昆虫 生态学和植被生态学, 属于无样方分析的方法之一. 它最早由 Clark 和 Evans 于 1954 年提出, 其基本理论 是通过比较样地内种群的实际分布与假设的随机分 布的差异, 借以作出种群空间分布类型的判断 ${ }^{[16 ~ 18]}$. 在本文中对马流感疫情发生的格局分析主要基于比 较疫情实际分布与理论随机分布的差异显著性, 这 一指标主要通过对事件点邻域平均距离与理论随机 格局点对的期望平均距离的比值差异性来表达 ${ }^{[10 ~ 12]}$. 目前格局分析的方法已广泛应用于昆虫生态学、森林 生态学等学科 ${ }^{[10,14,16 ~ 18]}$, 在涉及到禽流感 ${ }^{[11,12]}$ 、梅 毒 ${ }^{[21]}$ 等传染病流行病学的扩散模式、风险评估、环 境污染扩散、流行病学调查和监测等多个领域也广为 应用. 格局分析依赖于空间尺度的选择.

(iii) 集聚度探测和似然比检验 (likelihood ratio test). 地理风险格局分析可以为确定病例之间的空 间关系提供度量, 但病例之间集聚程度则需要通过 集聚度探测和统计检验来说明. 借鉴 Bernoulli 统计 模型 ${ }^{[27]}$, 对挖掘的分析数据的结构进行病例-对照的 设计. 在全国尺度上, 病例-对照设计的样本群体大 小为 2357 个, 涵盖全国所有区域. 借鉴 Kulldorff 的 统计检验方法, 开展基于 Bernoulli 统计模型的病例对照分布的研究. Kulldorff 的统计检验方法在近几年 来是分析集聚度的最为有效的方法之一, Kulldorff 统 计检验的基本原理是在研究区域内基于可变的探测 单元的病例-对照统计分布及分析检验来对整个区域 进行多次探测模拟和检验. 基于 Bernoulli 统计的病 
例-对照分布模型是在每个选定探测区域内的发病状 况和该区域以外的发病状况进行比较. 本研究的病 例-对照设计就是基于 Bernoulli 统计模型开展探测和 模拟, 并借鉴似然比方法进行统计检验, 从而开展对 病例分布进行模拟和集聚程度的探测。基于 Bernoulli 统计模型的似然比检验模型可以用下述公 式表达:

$$
L(Z, p, q)=p^{n^{2}}(1-p)^{\mu(Z)-n^{2}} q^{n_{G}-n^{2}}(1-q)^{(\mu(G)-\mu(Z))-\left(n_{G}-n^{2}\right)},
$$

其中 $n^{z}$ 指代在区域 $Z$ 内的病例样点, 本文中指代选择 探测模拟区域内报道的马流感病例; $n_{G}$ 指代在整个研 究区域 $G$ 内的病例样点, 本文中指代实验所涉及的 全国区域内的马流感病例; $Z$ 指代经过蒙特卡罗模拟 和统计检验后产生的积聚区域; $G$ 指代实验研究的区 域; $\mu(Z)$ 指代在所选的集聚区域 $Z$ 内的全部病例-对 照的样本数, $\mu(G)$ 指代在研究区域内的全部病例-对 照的样本数, $\mu($ ) 用来表示对函数取整数值. 每一个 样本数的取值只有 2 种选择, 可以是“是”、“不是”或 “有”、“无”, 本研究选择“发生”或“不发生”. $p$ 指代任 何一病例被选为落人聚集病例的模拟区域的概率, $q$ 为任何一病例点位被选为落人非聚集病例的模拟区 域的概率.

对于给定的一个区域 $Z$, 用 $p_{z}, q_{z}$ 代表任一病例 在区域 $Z$ 内或之外的分布概率, 然后我们计算 $L_{z}=\sup _{p>q} L\left(Z, p_{z}, q_{z}\right), \hat{Z}$ 指代 $L_{z}$ 所取的最大值, 这 就是最为可能的集聚病例所在区域. 同时, 我们利用 似然比作统计检验. 使 $L_{\mathrm{o}}=\sup _{p=q} L\left(Z, p_{z}, q_{z}\right)$ 为无效 假设 (即无集聚度) 的似然值, 利用 $\lambda=L_{\hat{乏}} / L_{0}$ 来计算 统计检验的值. 病例-对照的统计检验推断是基于蒙 特卡罗数值模拟的结果.

\section{2 结果}

\section{1 我国马属动物的养殖及其分布状况}

中国是国际上的养马大国, 马匹养殖数量多年 以来一直维持在 800 万匹左右, 存栏份额占全球马存 栏总量的 $15 \%$ 左右. 但从 2000 年以来, 中国马的养 殖数量有所减小 (见图 1 所示), 2000 年末存栏数量为 876.8 万匹, 2001 年为 826.2 万匹, 到 2004 年和 2005 年存栏数量分别下降到 763.85 和 777.71 万匹, 整体上, 马的养殖数量在下降.

从国内马匹养殖区间分布的差异变化来看, 在 2000 2006 年之间, 吉林、黑龙江、河北、河南、辽宁、 青海、山东、新疆、云南等 12 个省、市和自治区的 马匹的年末存栏数量有所减小, 而广西、贵州、四川、 西藏等 4 个省、市和自治区的马匹的存栏数量有所增 加, 其他一些省、市和自治区的马匹的存栏数量维持 在相对平稳的水平. 2006 年中国共存栏马匹约 780 万 匹左右, 养殖和存栏数量较大的省、市和自治区依次 为新疆、四川、云南、贵州、内蒙古和吉林, 存栏数 量分别为 $95.78,84.79,79.76,78.53,68.74$ 和 57.83 万 匹等, 黑龙江、西藏、广西、河北等省、市和自治区 的存栏数量也较大, 分别达到 $45.5,42.5,39.86$ 和 35.53 万匹等. 此外, 驴、骡等其他马属动物约 1165 万匹左右, 其中驴的养殖数量为 791 万匹左右, 养殖 和存栏数量较大的省、市和自治区为山东、内蒙古、 辽宁、河北、甘肃和新疆; 骡的养殖存栏数量为 374 万头左右, 养殖和存栏数量较多的省、市和自治区为 内蒙古、河北、甘肃和云南等, 见图 1 及 2 所示.

在马属动物养殖密度上, 云南、四川、甘肃、山
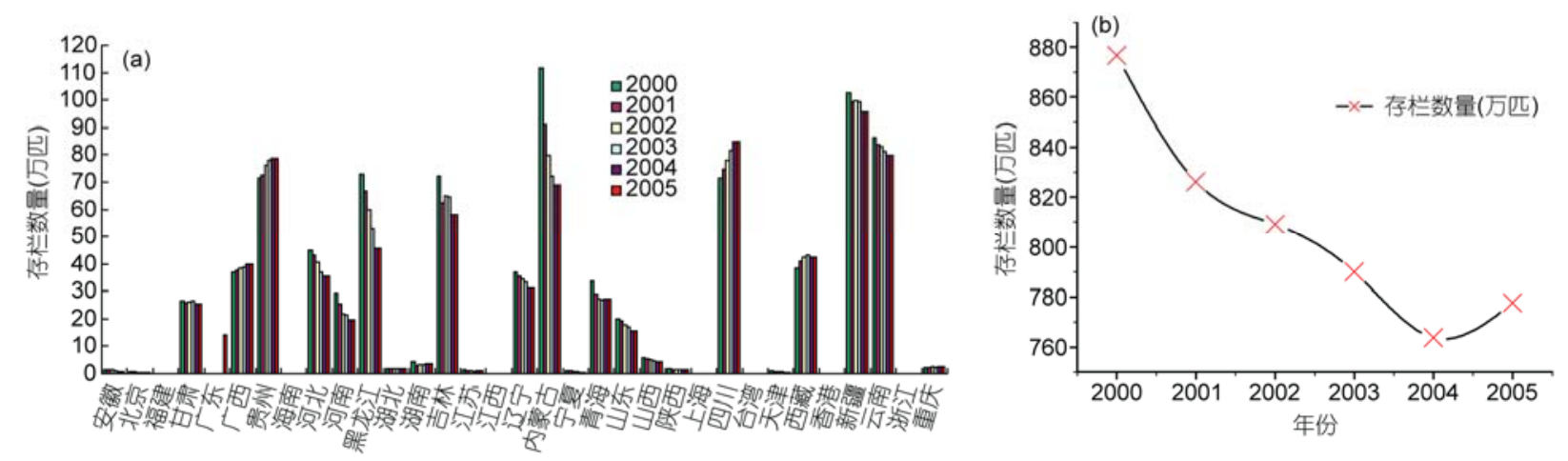

图 1 中国 2000 2006 年马存栏数量分布

(a) 区间分布; (b) 时间分布 
东、河北、宁夏、河南、辽宁、吉林等省、市和自治 区的养殖和存栏密度都较大. 2006 年统计数据显示, 上述这些区域每平方公里养殖数量在 3 匹以上, 而青 海、西藏以及南方大部分省、市和自治区的养殖密度 都较小, 每平方公里养殖数量在 1 匹以下, 见图 2 所 示. 2006 年统计资料显示, 我国共有种用马场的数量 为 17 个左右, 主要分布在广西、江苏、辽宁、内蒙 古、青海、陕西、新疆、北京、河北、甘肃、吉林和 云南等省、市和自治区, 其中以北京、河北、甘肃、 吉林和云南等的种马场为多, 这些省、市和自治区的 种马场基本都有至少 2 个用于配种, 见图 2 所示.

\section{2 中国马流感报道病例的病例-对照设计}

马流感曾在我国多个省、市和自治区发生(见 表 1), 最近 30 多年内, 我国至少发生 3 次较大规模 的马流感流行 ${ }^{[22,23]}$. 第一次发生在 1974年 6 月, 新疆 与前苏联接壤的伊梨、博尔塔拉、塔城等地区发生马 流感疫情, 并很快蔓延至全自治区 11 个市州, 1974 年冬继续向南向东传播蔓延, 先后传播到青海、甘
肃、内蒙古等 17 个省、市和自治区，流行的毒株属 于 H7N7 亚型, 以 $\mathrm{A}$ /马/京防 74-1 为代表, 与 1956 年 国外分离的毒株 $\mathrm{A} /$ 马/1/布拉格/1/56(H7N7)在抗原上 很相似.

第二次起始于 1989 年, 主要发生在吉林、黑龙 江和内蒙古, 流行的毒株属于 H3N8 亚型, 其内部 6 个基因可能来自禽流感病毒, 与当时和现今国外流 行的 H3N8 亚型马流感毒株对比, 在抗原性和遗传特 性上有显著差别.

第三次起始于 1992 年秋, 止于 1994 年初, 流行 范围包括我国西北、华北和西南地区, 病毒仍为 H3N8 亚型, 但和第二次大流行的 H3N8 亚型病毒差 别显著, 而与 1989 1992 年在英国、荷兰等多个欧洲 国家流行的 H3N8 亚型马流感病毒相似 ${ }^{[28]}$. 此外, 我 国香港地区 1992 年暴发赛马流感, 病原和该时期欧 洲多个国家以及我国流行的马流感病毒相似 ${ }^{[29]}$. 自 20 世纪 50 年代以来, 我国报道的马流感疫情的分布 及其对照设计见表 1 及图 3 所示.

在 2000 2003 年度, 各地报道的马流感疫情较少,
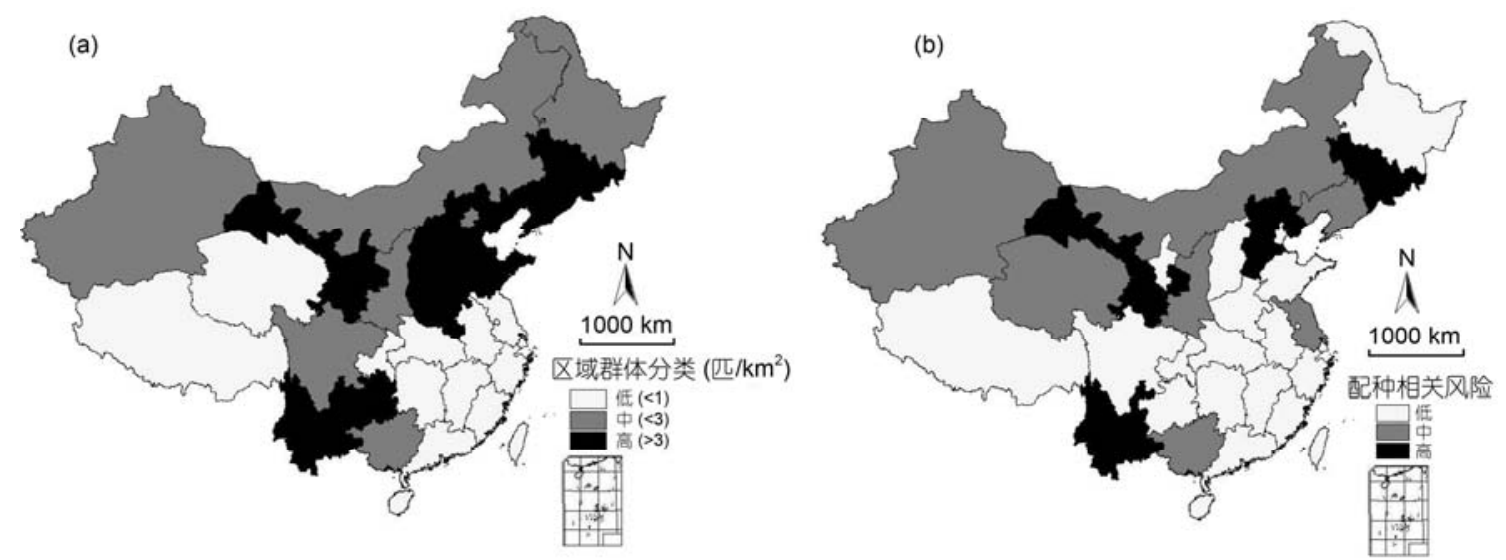

图 22006 年我国马属动物基于养殖和种马场分布的格局分类

(a) 养殖分布; (b) 种马场分布

表 1 我国 20 世纪 50 年代以来马流感发病状况 ${ }^{\text {a) }}$

\begin{tabular}{|c|c|c|c|c|}
\hline 时期(年代) & 报道县数 & 发病数量(万匹) & 死亡数(万匹) & 分布地区 \\
\hline $1950 \sim 1960$ & 18 & 1.16 & 461 & 蒙、豫、辽、青、闽、宁 \\
\hline $1960 \sim 1970$ & 23 & 2.56 & 45 & 辽、豫、闽、青、宁、冀、新 \\
\hline $1970 \sim 1980$ & 424 & 246.21 & 6319 & $\begin{array}{l}\text { 豫、闽、蒙、辽、青、宁、冀、甘、新、津、吉、苏、陕、 } \\
\text { 鲁、川、贵、藏 }\end{array}$ \\
\hline $1980 \sim 1990$ & 26 & 19.83 & 253 & 蒙、豫、青、吉、黑、宁、苏 \\
\hline $1990 \sim 2000$ & - & - & - & 西部、西北、华北和西南地区 \\
\hline
\end{tabular}

a) 数据来源于中国动物疫病志及各省、市和自治区的动物疫病志 

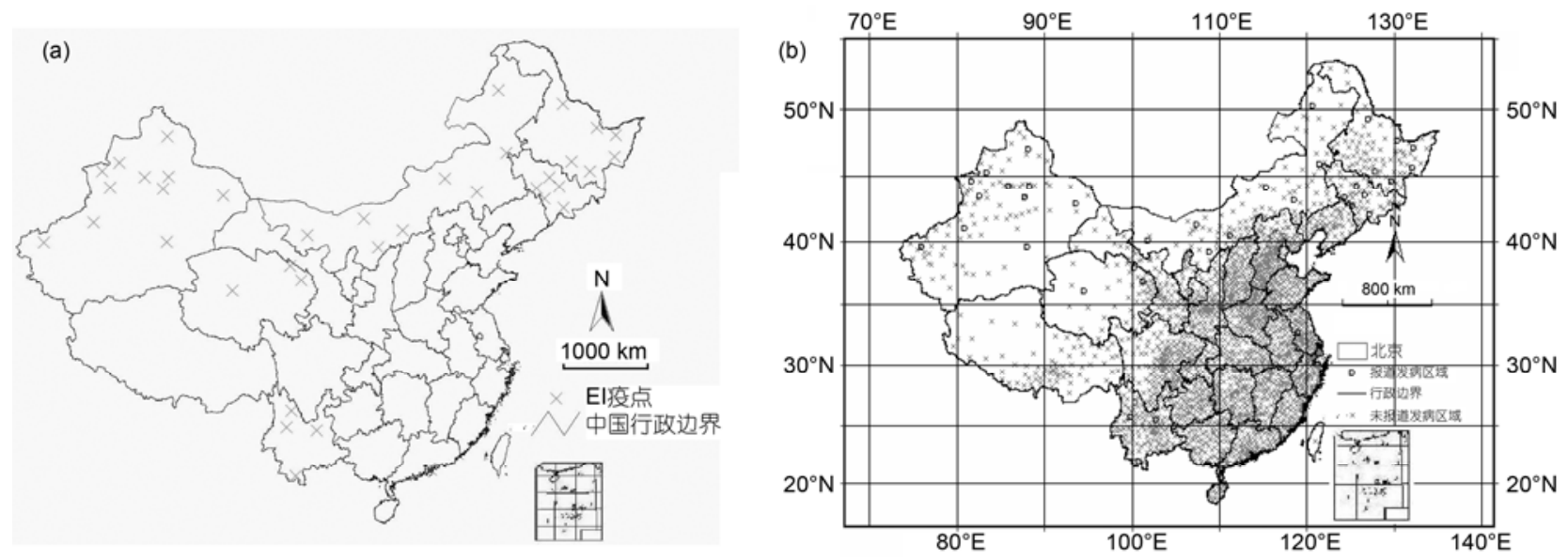

图 3 我国 1950 2000 年度马流感发生状况分布及其病例-对照设计

(a) 病例分布; (b) 病例-对照设计

疫情影响有限, 但随着经济、社会活动以及人、畜等 动物及产品的流动频率增加, 马匹异地流动频繁, 使 得各地 2003 年以后马流感报道的疫情有增加趋势. 马流感病例分布状况及病例-对照的设计见图 4 所示.

\section{3 中国马流感病例发生的集聚度探测及地理风 险格局分析}

(i) 历史病例探测. 自 20 世纪 50 年代以来, 中国先后发生过 3 次较大规模马流感疫情, 报道病 例主要分布在中国北方省、市和自治区, 包括新疆、青 海、内蒙古、黑龙江、吉林等, 此外西南地区云南省 也有病例报道. 病例分布及基于 Bernoulli 模型分布 的病例-对照设计见图 3 所示. 利用蒙特卡罗模拟及 似然比统计检验, 对我国 2357 个样本区的病例-对照 研究区域进行基于病例分布的集聚度探测模拟和统 计检验, 结果显示, 我国新疆阿勒泰地区的坐标点位 为 $(6960036,4432260)(P<0.001, R=1165880 \mathrm{M}, R R=$ 9.11)报道发生的病例, 黑龙江大兴安岭地区的坐标 点位 $(9768346,5338305)(P<0.001, R=1174519 \mathrm{M}$, $R R=6.69)$ 报道发生的病例区域有可能是马流感发生 频次高、病例发生最为集聚的区域, 见图 5 所示.

(ii) 2000 2008 年度病例探测. 经过 20 世纪三 次较大规模疫情后, 2000 年以来, 我国马流感疫情发 展进人较低发病水平. 但随着经济和社会活动以及 人畜流动频率增加, 近年来马流感疫情有反弹趋势. 2003 年 3 月, 甘肃和青海地区报道发生 2 起马流感疫 情, 2007 年 9 月起新疆 7 个市州连续发生 19 起马流 感疫情 ${ }^{[12]}$. 对 2000 2008 年间报道的 21 起马流感病
例进行统计学分析, 结果表明, 这 21 起疫情的空间 关联性强, 疫点点位之间的空间关系显著, $R$ 统计值 为 0.34315 , 标准化的 $Z$ 值为 5.7588 , 远大于统计检 验的临界值, $95 \%$ 置信区间内可以认为, 2003 年以来 的疫情有较强的空间关联性和连续性. 为进一步探 究病例空间分布的内在驱动, 借鉴 Bernoulli 统计模 型的病例-对照设计(见图 4所示)和蒙特卡罗模拟方 法对病例分布进行探测模拟, 似然比统计检验显示, 新疆伊犁州和巴音郭楞蒙古自治州交界地区坐标为 $(6460039.00,4277548.50)(P<0.001, R=748797.06 \mathrm{M}$, $R R=273.94)$ 的病例及附近区域的马流感疫情发生集 聚程度最高, $R R$ 值达到 273.94, 分布见图 6 所示, 提 示该地区马属动物群体及其养殖环境中可能存在马 流行性感冒发生的必要风险因素.

\section{3 讨论}

集聚度探测在流行病学领域有广泛的应用, 可 以为流行病学调查、病例统计、信息汇总、回顾性分 析等提供思路, 对病例分布特点探寻、风险因素分析 和识别、主动监测和抽样调查等研究领域也都有非常 积极的意义, 特别是在流行病学调查设计、疫病风险 区域化管理、动物及动物产品移动控制和监管等方面 有实际的用途, 但目前我国兽医流行病学领域内尚 未就这些方面开展系统的研究和有效的工作. 本文基 于科技文献、科研资料、中国动物疫病志及有关省、市 和自治区动物疫病志等报道的马流行性感冒病例分布 数据, 通过病例-对照设计的方法和 Bernoulli 统计模 型, 借鉴 Kulldorff 的统计检验方法开展马流感病例的 
(a)

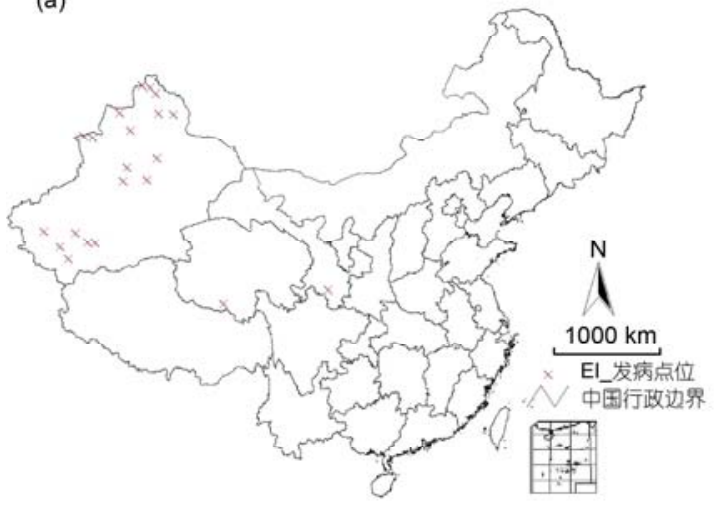

(b)

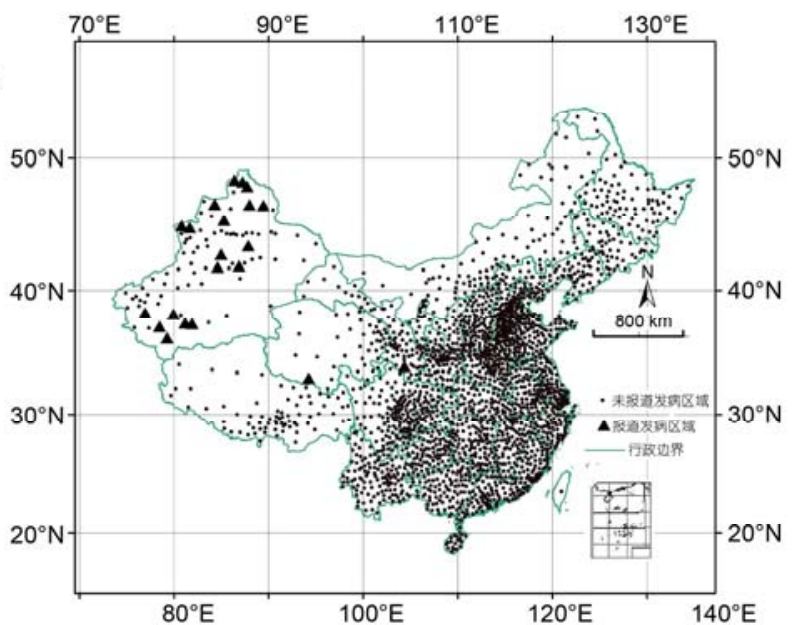

图 4 我国 2000 2008 年度马流感发生状况分布及其病例-对照设计 (a) 病例分布; (b) 病例-对照设计

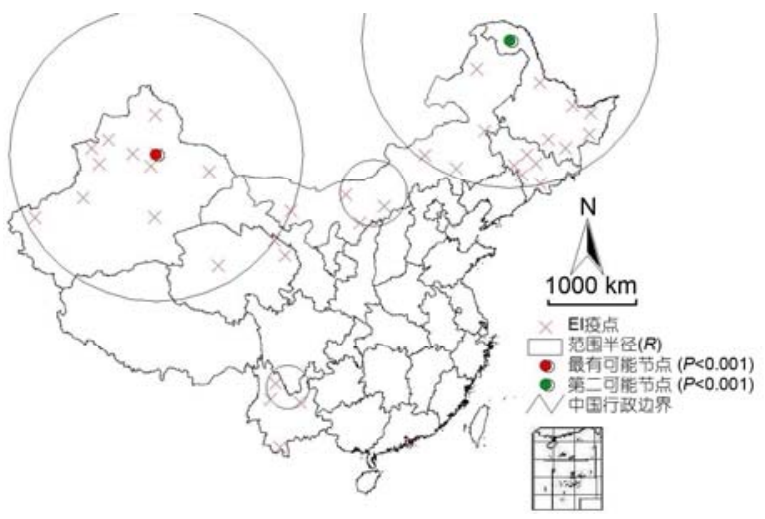

图 5 中国马流感历史病例集聚度分析

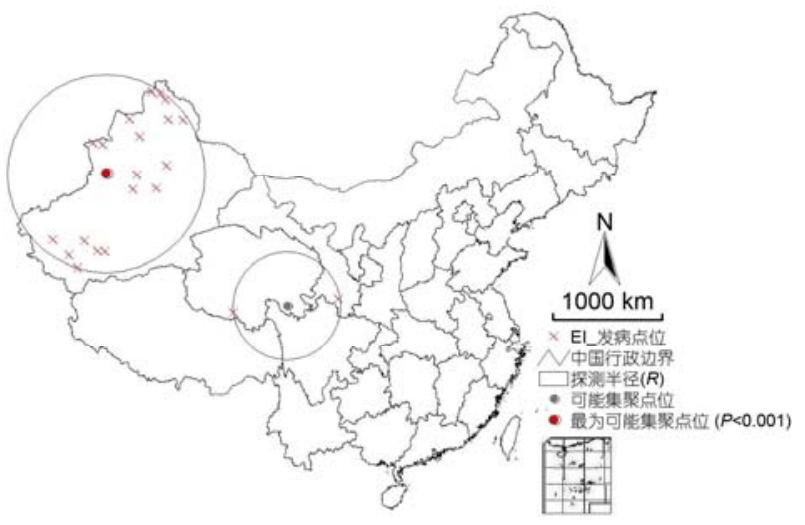

图 6 中国 2000 2008 年度马流感病例集聚度分析

集聚度探测研究, 在方法上是我国兽医流行病学领域 的一个探索和尝试, 但由于数据来源及数据类型、精 度、质量等方面存在的固有特点, 导致本研究对马流
感病例信息的挖掘和占有相对有限, 也会对研究结论 产生影响.

马流感在我国的发生有久远的历史，仅建国后 我国就有 3 次较大规模的暴发和流行. 据中国动物疫 病志记载, 在建国到 1990 年全国 40 年间共发生 260 多万匹次的马属动物感染马流感的疫情, 保守估计 病死马超过 7 千多匹, 死亡率为 $0.26 \%$. 马流行性感 冒在我国被列为第三类动物疫病名录, 并不是国家 强制报告的一、二类重要疫病, 因而我国目前对马流 行性感冒疫情的防控还没有统一的防治技术规范出 台, 包括产地检疫的标准、跨地区移动和运输的风险 管理等; 在出人境方面, 马流行性感冒也没有列人 《中华人民共和国进境动物一、二、三类传染病、寄 生虫病名录》, 目前为止对进境马匹的马流感检疫、 监管尚缺乏统一的规范和风险控制的法律依据和基 础. 但大范围内马流感传染源和易感动物普遍存在, 疫情传播又非常迅速，同时国内易感动物免疫接种 率较低，马流感疫苗的研发尚有待突破，故而这些不 利因素都是马流感风险管理所面临的主要问题. 鉴 于此, 提出以下几点风险管理的建议.

(1) 逐步健全防疫体系, 提高科学管理水平. 目 前国内在马匹的配种、饲养以及马匹的远距离移动等 方面尚未构建起有效的防疫体系. 缺乏具体的有可 操作性的风险管理规范和检疫监督标准、法规等增加 了马流感和其他疫病病例频繁发生的系统风险.

(2) 开展风险管理的研究. 建议适时启动马属动 物疫病风险的区域区划的研究, 适时起草、出台和发 
布马属动物产地检疫标准、有关办法和规程. 风险的 区域区划是疫病控制和疫病风险管理的基础工作, 科学的风险区划可以高效、快捷地为疫病的控制和根 除提供技术支持.

（3）加强马流感疫苗和快速诊断试剂等技术产 品的研发. 疫苗和诊断试剂是有效的风险干预的基 础, 有效的疫苗和高效的诊断试剂是疫病控制的保障.

(4) 开展重点区域马流感的主动监测和免疫工 作. 马流感的发生和流行严重影响到我国赛马业的 健康发展, 加强重点区域马流感的主动监测, 特别是 赛马业发达、马术比赛频繁区域马属动物的 EI 状况 的监测, 对推动全国赛马业健康发展是有力的促进 和保障.

\section{4 结论}

（1）我国是马属动物养殖大国, 马流行性感冒在 我国局部地区的马属动物群体中曾有过较大范围的 发生. 回顾性分析表明, 我国建国后马流感发生主要 在西北和东北局部地区. 特别是 2000 年以后, 我国 马流感疫情主要在西北地区以新疆为中心, 在新疆、
青海和甘肃等省、市和自治区有报道. 目前马流行性 感冒的防控依然是马属动物风险管理的重点.

（2）地理风险格局分析表明，我国 2003 2008 年 度报道的新疆、青海等地区的 21 起疫情空间关联性 强, 疫点点位之间空间关系显著, $R$ 统计值为 0.34315 , 标准化的 $Z$ 值为 5.7588, 远大于统计检验的临界值, 95\%置信区间内可以认为 2003 2008 年之间发生的疫 情有较强的空间关系和连续性.

(3) 2003 2007 年度马流感病例集聚度探测表明, 新疆伊犁州和巴音郭楞蒙古自治州交界地区坐标为 (6460039.00, 4277548.50) $(P<0.001, R=7487976.06 \mathrm{M}$, $R R=273.94)$ 病例区集聚度为最高, $R R$ 值达到 273.94, 显示该病例区及附近区域很有可能存在马流感疫情 发生所需要的必要风险因素, 提示现阶段应该加强 对该区域马属动物的风险监管和主动监测.

（4）基于病例-对照的实验设计，对马流感病例 集聚度探测初步明确了现阶段我国马流感发生的大 尺度格局，即我国马流感发生的风险主要在西北局 部地区，但其风险有沿新疆、青海、内蒙古、东北及 京津地区一线扩散的趋势.

\section{参考文献}

1 杨建德，相文华. 我国马流感的研究现状. 黑龙江畜牧兽医, 2002, 3: 42-44

2 戴伶俐, 李雪峰, 相文化. 马流感诊断方法研究进展与应用概况. 中国预防兽医学报, 2010, 32: 157-160

3 Guo Y, Wang M, Kawaka Y, et al. Characterization of a new avain-like influenza virus from horse in China. Virology, 1992, 188: $245-255$

4 张志诚, 宋建德, 杨楠, 等. 全球马流感发生的风险研究. 中国动物检疫, 2010, 12: 45-48

5 Crawford P, Dubovi E, Castleman W, et al. Transmission of equine influenza virus to dogs. Science, 2005, 310: 482-485

6 Newton R, Cooke A, Elton D, et al. Canine influenza virus: Cross-species transmission from horses. Vet Rec, 2007, 161: 142-143

7 Janet M D, Anthony S B, Shona M, et al. Transmission of equine influenza virus to English foxhounds. Emerg Infect Dis, 2008, 14: 461-464

8 Davis M J, Garner G, East I J. Analysis of local spread of equine influenza in the Park Ridge region of Queensland. Transbound Emerg Dis, 2009, 56: 31-38

9 相文化. 中国马流感研究现状. 兽医导刊, 2009, 10: 18-19

10 张志诚, 孙江华, 黄保续, 等. 基于 GIS 松树萎䔍病发生格局的研究. 浙江大学学报, 2006, 32: 551-556

11 张志诚, 李长友, 黄保续, 等. 基于 GIS 的禽流感发生格局研究. 浙江大学学报, 2008, 34: 347-354

12 张志诚, 李长友, 黄保续, 等. 中国禽群高致病禽流感发生状况及其风险预测. 畜牧兽医学报, 2010, 41: 455-462

13 张志诚, 李蕾, 王志亮, 等. 地理风险分析在动物卫生与流行病学中的应用. 中国动物检疫, 2009, 11: 73-75

14 Zhang Z C, Hua O, Niu H S, et al. Spatial analysis on the occurrence of pine wilt disease point range expansion in Anhui province. Russ J Nematol, 2005, 13: 167

15 张志诚, 黄昫, 包静月，等. 基于“风险邻近”的全球尺度非洲猪瘟发生状况及其输人风险模型构建. 畜牧兽医学报, 2011, 42: 82-91

16 Moeur M. Charasterizing spatial patterns of trees using stem-mapped data. For Sci, 1993, 39: 756-775

17 Kint V, Lust N, Ferris R, et al. Quantification of forest stand structure applied to Scots pine (Pinus sylvestris L.) forests. Investigación Agraria: Sistemas y Recursos Forestales, 2000, Fuera de serie 1: 147-163

戴小华, 余世孝. GIS 支持下的种群分布格局分析. 中山大学学报, 2003, 42: 75-78 


\section{Case-control study on cluster detection of equine influenza in China}

\author{
ZHANG ZhiCheng ${ }^{1}$, WANG ZhiLiang ${ }^{1}$, HOU ZheSheng ${ }^{2}$, XIANG WenHua ${ }^{3} \&$ WANG LiJian ${ }^{4}$ \\ ${ }^{1}$ National Research Center for Exotic Animal Disease, China Animal Health and Epidemiology Center, Qingdao 266032, China; \\ ${ }^{2}$ School of Civil Engineering, Yantai University, Yantai 264005, China; \\ ${ }^{3}$ Harbin Veterinary Research Institute, Chinese Academy of Agricultural Sciences, Harbin 150001, China; \\ ${ }^{4}$ Xinjiang Academy of Animal Sciences, Urumqi 830000, China
}

This study investigated the distribution patterns of reported equine influenza (EI) cases in China. Geographical risk pattern analysis of a retrospective case-control study was assessed using geographical information sciences and the likelihood ratio test. The analysis showed that: (1) Equine production in China accounts for $15 \%$ of the worldwide total, among which, the highest densities were identified in Yunnan, Gansu, Hebei, Liaoning and Jiling administrative regions. Qinghai, Xizang and most southern administrative regions had relatively low densities. (2) Retrospective studies revealed three major EI epidemics across China pre-2000, which were mainly distributed in northwestern and northeastern regions. (3) EI cases were also reported in China after 2000, mainly in the Xingjiang administrative region and neighboring regions. Geographical risk pattern analysis suggested these reported EI cases were significantly spatial related in $95 \%$ confidence interval (CI), with an $R$-value of 0.3415 , standard $Z$-value of 5.7588 , a higher critical value compared with the theoretic random distribution. (4) Likelihood ratio testing of the Bernoulli-based case-control study for pre-2000 cases showed that cases positioned at site $(6960036,4432260)(P<0.001, R=1165880 \mathrm{M}, R R=9.11)$ were most likely clustered, as were cases at site $(9768346,5338305)(P<0.001, R=1174519 \mathrm{M}, R R=6.69)$. From a risk management perspective, these two regions should be the focus of active surveillance. (5) Likelihood ratio testing of the Bernoulli-based case-control study for the EI cases reported after 2000 showed that cases positioned at $(6460039.00,4277548.50)(P<0.001, R=7487976.06 \mathrm{M}, R R=273.94)$ and nearby locations were most likely clustered. This indicated the existence of risk factors associated with EI infestation in these regions, and active surveillances should therefore be conducted. In this study, case-control cluster detection of EI occurrence indicated that northwestern China is currently the main region at risk of EI outbreak. Timely implementation of active surveillance programs and enhanced monitoring of equine movement should be carried out.

case control, cluster, equine influenza, geographical risk pattern, active surveillances

doi: 10.1360/972011-384 